\title{
OS EFEITOS DA RADIAÇÃO ELETROMAGNÉTICA NA VIDA DO SER HUMANO : UMA ANÁLISE DO PARADIGMA AMBIENTAL
}

\author{
The effects of eletromagnetic radiation in the \\ life of the human being: an analysis of the \\ environmental paradigm \\ Edson Leite Ribeiro* \\ Martha Bulcão Pessoa*:
}

\section{Resumo}

Diferentes formas de energia vêm sendo utilizadas com o objetivo de trazer mais conforto e rapidez a nossa sociedade, porém há fontes de energias que são bem mais conhecidas pela população, (como a atômica e a elétrica) do que a energia eletromagnética, mas nem por isso esta é menos utilizada que as demais. É inegável a constante presença, ainda que imperceptível, da radiação eletromagnética no cotidiano das pessoas, através dos mais diferentes tipos de aparelhos tecnológicos e isto traz consequiências para o meio ambiente. Há um imenso número de antenas, computadores e celulares sendo utilizados neste exato momento por milhares de pessoas; por esta razão é necessária uma análise do paradigma ambiental para uma avaliação dos potenciais efeitos da radiação eletromagnética pela população. Foi realizada uma pesquisa bibliográfica para a obtenção de dados e gráficos explicativos sobre os efeitos do eletromagnetismo e suas implicações na vida do ser humano.

Palavras-chave: Energia. Radiação eletromagnética. Meio ambiente.

* Professor do Programa Regional de Pós-Graduação em Desenvolvimento e Meio Ambiente, da Universidade Federal da Paraíba; especialista em Controle Ambiental pela Universidade de Brasília; mestre em Desenvolvimento Urbano pela Universidade Federal de Pernambuco; doutor em Engenharia Civil pela Universidade de São Paulo. Email: edlribeiro@gmail.com

** Especialista em Direito Ambiental pelo Centro de Ciências Jurídicas da Universidade Federal da Paraíba; Mestranda do Programa de Pós-Graduação em Gerenciamento Ambiental pela Universidade Federal da Paraíba. Email: jampessoa@terra.com.br 


\section{Abstract}

Different forms of energy has been used with the objective to bring more comfort and speed to our society, but there are energy sources that are more well-known by the population (such as the atomic and the electric ones) than the electromagnetic energy, but even so, the latter isn't less used comparing with the others. It is undeniable the constant presence, although imperceptible, of the electromagnetic radiation in people's life, through different types of technological equipments, and this brings consequences to the environment. There is a huge number of antennas, computers and cell phones been used in this exact moment by millions of people, and for this reason it is necessary an analysis of the environmental paradigm for an evaluation of the potential effects of the electromagnetic radiation on the population. A bibliographical research was realized.in order to get data and clarifying graphs about the effects of the electromagnetism and its implications in the life of the human being

Keywords: Energy, electromagnetic radiation, environment.

\section{INTRODUÇÃO}

Muitas mudanças em nossa sociedade ocorreram, e ainda ocorrem, por causa da energia. Uma das condições indispensáveis para o desenvolvimento econômico é o abastecimento energético eficiente, mas também é importante salientar que esta mesma energia gerada, em quantidades cada vez maiores, é responsável por uma grande parte de desastres ambientais ocorridos nos últimos anos no mundo.

A energia eletromagnética é bem menos conhecida pela população do que a atômica e a elétrica, por exemplo, mas este tipo de energia imperceptível é extremamente utilizada em nossa sociedade e pode provocar, dependendo do tempo e nível de exposição, riscos à saúde. A radiação eletromagnética passa através de nós todos os dias e não percebemos sua existência. Ela está presente em diversos tipos de equipamentos tecnológicos utilizados pelo ser humano, como: antenas, computadores e celulares, por exemplo. 
O consumo desenfreado e o uso intensivo de alguns tipos de tecnologias, como é o caso dos computadores e telefones celulares, pode vir a se tornar um sério problema ambiental, principalmente em grandes centros urbanos onde as pessoas consomem produtos tecnológicos de uma forma cada vez mais "descartável". A produção e o consumo de telefones celulares aumentou de forma rapidíssima. A telefonia celular iniciou-se em 1984, mas em 2000 já eram 700 milhões de aparelhos e no fim do $1^{\circ}$. trimestre de 2007 já atingiam 2,805 bilhões de telefones celulares em todo o mundo.

A utilização em massa de novas tecnologias vem desassociada de um estudo sobre o impacto da introdução destes materiais em nosso cotidiano,

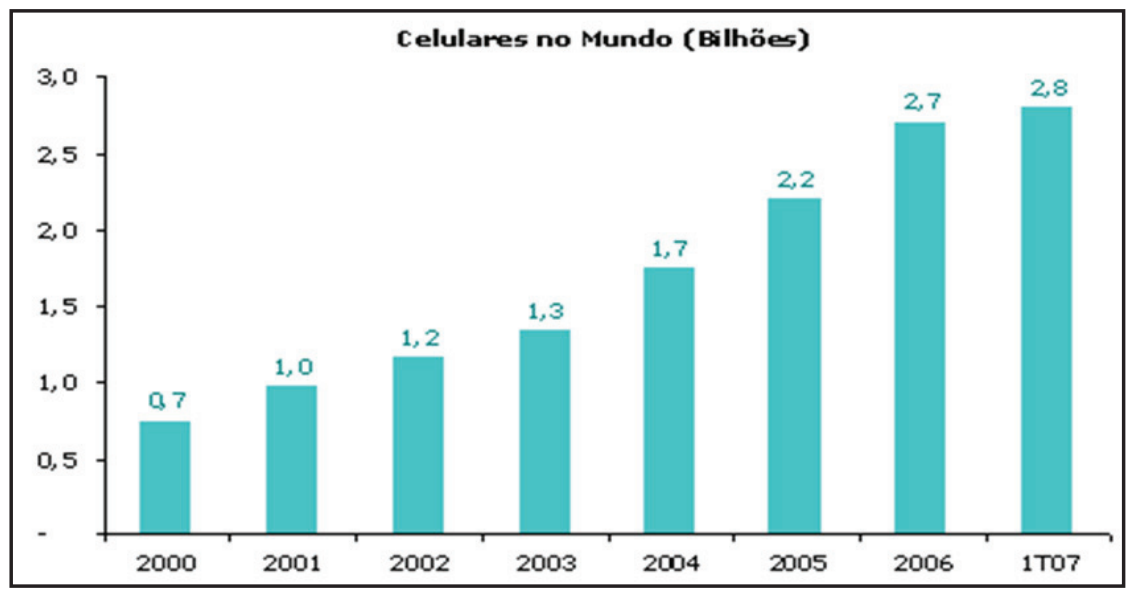

Figura 01 - Evolução de telefones celulares no mundo

em nossa saúde, em nosso trabalho, enfim, no ambiente como um todo, fazendo-nos reféns da chamada sociedade de risco de Ulrich Beck. ${ }^{1}$

É inegável que as pessoas sentem-se atraídas pela tecnologia; afinal ela sempre exerceu influências no ser humano, por isso, é importante elucidar e avaliar os modos de implementação de novos equipamentos tecnológicos e suas formas de energia, e não somente a conveniência, o conforto e a comodidade que elas nos propiciam. A comunidade deve 
apropriar-se do maior número de informações acerca das tecnologias utilizadas e desenvolvidas em nossa sociedade, na qual o livre exercício da atividade econômica deve estar limitado pelo princípio da dignidade humana, pelo direito à vida e ao meio ambiente devidamente equilibrado. Apresentando-se, assim, restrições às atividades que venham de encontro à sustentabilidade ambiental e, portanto, à sadia qualidade de vida de todos. É interessante notar, pelo ranking mundial de aparelhos celulares, países de melhor consciência e nível cultural, como os países europeus e o Canadá, não se apresentam como os melhores mercados de celulares. O Brasil está em quinto lugar e só é ultrapassado por China, EUA, Índia e Rússia. Ainda que se considere que os países com melhor mercado são os mais populosos, há que se considerar que, relativamente, estes países, também têm, proporcionalmente, mais celulares.

\begin{tabular}{|l|c|c|c|c|}
\hline \hline País/Ano & 2004 & 2005 & 2006 & $1^{\circ} . \mathrm{T} / 2007$ \\
\hline China & 335 & 393 & 461 & 481 \\
\hline Estados Unidos & 181 & 208 & 233 & $237^{(1)}$ \\
\hline Índia & 48 & 76 & 149 & 166 \\
\hline Rússia & 74 & 126 & 152 & 155 \\
\hline Brasil & 66 & 86 & 99,9 & 102,2 \\
\hline Japão & 91 & 95 & 99,8 & 101,7 \\
\hline
\end{tabular}

Quadro 01 - Principais mercados da Telefonia Celular no Mundo (20042007)

(1) Estimativa em milhões de aparelhos no ano de 2007

Fonte: UIT e Wireless Intelligence (Ovum/GSM Association) (2007)

Para a realização do presente artigo foram utilizadas fontes bibliográficas que proporcionassem a elaboração e obtenção de dados explicativos sobre os efeitos do eletromagnetismo e suas implicações na vida do ser humano, de forma a facilitar uma análise do paradigma ambiental e uma avaliação dos potenciais efeitos da radiação eletromagnética pela população. 


\section{ENERGIA E MEIO AMBIENTE}

O ser humano sempre se esforçou em criar um ambiente que pudesse satisfazer suas necessidades, quer sejam materiais, espirituais, emocionais e intelectuais. Nossas cidades e construções, portanto, refletem os valores, mas também as contradições de nossa sociedade.

$\mathrm{O}$ crescimento populacional, associado a um desequilibrado e injusto sistema econômico e social, gera uma desorganizada ocupação do solo, com diversos tipos de construções mal planejadas e inadequadas para se morar. Tanto a falta de espaço, como a superpopulação e as questões econômicas, acabam propiciando conseqüências indesejáveis, tais como: poluição, com acúmulo de lixo, e doenças.

Os cânceres e as alergias crônicas são alguns exemplos de males que se multiplicam nos últimos anos, e estes problemas podem estar associados às modificações no ambiente natural e à estruturas ambientais urbanas inadequadas. $O$ fato é que modificamos o ambiente incessantemente, sem pararmos para refletir sobre o impacto destas alterações ambientais em nossas vidas.

A questão energética é de fundamental importância no contexto ambiental e de desenvolvimento sustentável. É nosso dever a busca de uma maior eficiência energética, evitando ao máximo os danos ambientais, de modo que haja um desenvolvimento sustentável, já que o setor energético produz impactos ambientais em toda sua cadeia de desenvolvimento, desde a captura de recursos básicos naturais até os usos finais de consumo.

Nos últimos dez anos, tem ocorrido uma expansão do uso de equipamentos eletrônicos e elétricos que emitem muito calor em nossos locais de trabalho e em nossas casas (o computador, por exemplo, pode gerar dez vezes mais calor que o corpo humano). ${ }^{2}$

Não nos questionamos sobre os riscos das tecnologias à nossa saúde, buscamos o conforto e a comodidade a qualquer preço, acostumando-nos e adaptando-nos lentamente a algo que pode nos trazer danos futuros; é a chamada Síndrome do Sapo Cozido: 
Um sapo pula dentro de uma panela com água que está sendo gradualmente aquecida. À medida que a água vai esquentando, o sapo vai adaptando a temperatura de seu corpo à da água, e continua a adaptá-la quando a água esquenta ainda mais - até que, finalmente, o sapo é cozido vivo. ${ }^{3}$

Portanto, essa capacidade de adaptação do ser humano ao meio ambiente modificado deve ser analisada e estudada conscientemente, a fim de que não fiquemos como o sapo, literalmente, cozido.

Tudo no universo independente de tamanho ou substância, emite um campo de energia. Faz-se assim, necessária, uma conceituação do que é a energia:

Energia. [ Do gr. enérgeia, pelo lat. energia.] S. f. 1. Maneira como se exerce uma força. (...) 5. Fís. Propriedade de um sistema que the permite realizar trabalho. [A energia pode ter várias formas (calorífica, cinética, elétrica, eletromagnética, mecânica, potencial, química, radiante), transformáveis umas nas outras, e cada uma capaz de provocar fenômenos bem determinados e característicos nos sistemas físicos. Em todas as transformações de energia há completa conservação dela; isto é, a energia não pode ser criada, mas apenas transformada (primeiro princípio da termodinâmica). A massa de um corpo pode-se transformar em energia, e a energia sob forma radiante pode transformar-se em um corpúsculo com massa]. ${ }^{4}$

\section{O ESPECTRO ELETROMAGNÉTICO}

Espectro eletromagnético. Fís. A distribuição das radiações eletromagnéticas em função do comprimento de onda (...), desde os raios gama, de menor comprimento, até as ondas longas de rádio. ${ }^{5}$

As Radiações Eletromagnéticas são ondas provenientes de campos elétricos e magnéticos variantes no tempo, que não estão confinadas ou guiadas e se propagam no espaço. 
Todo meio de comunicação que utiliza a antena para a difusão de informações submete-se às regras do direito de antena, no qual o espectro magnético constitui um processo de utilização de um bem ambiental.

Constatou-se, diante de experimentos físicos, que há uma variação ampla e contínua no comprimento e frequiência das ondas eletromagnéticas. Concluiu-se que pelo ar viajam ondas magnéticas que transportam um número cada vez maior de sinais, como: os de telefone, os de rádio, os de televisores, etc.

Não imaginamos que em nossas vidas possam existir milhares de intensidades, amplitudes e freqüências de ondas eletromagnéticas que vão e vêm carregando imagens e mensagens por toda parte no mundo. Particularmente nas cidades, este tráfego de ondas é ainda mais intenso. E, embora não possamos ver, estas ondas podem, também, atravessar a ionosfera terrestre, a mais de mil metros de altitude, e propagar-se pelo universo a fora.

O eletromagnetismo é considerado, pelos cientistas, uma das forças fundamentais que compõem o universo, e mesmo não se conhecendo tudo sobre esse tipo de energia, ela tem sido amplamente utilizada e explorada. Depois que se descobriu que a onda eletromagnética pode propagar-se por longas distâncias, a tendência é de aperfeiçoar novas técnicas para carregar cada vez mais informações por maiores distâncias.

A radiação, mesmo sendo um fenômeno único, é classificada pela ciência de acordo com o número de vezes que oscila em cada segundo, medida essa que se expressa em "Hertz" $(\mathrm{Hz})$. Os diferentes tipos de frequiência indicam diferentes tipos de radiação, o que deu origem ao chamado ESPECTRO ELETROMAGNÉTICO. Observe a figura a seguir.

\section{EFEITOS DA EXPOSIÇÃO A CAMPOS ELETROMAGNÉTICOS}

Todos os organismos são sensíveis a energias eletromagnéticas; sem energia nosso organismo não conseguiria sobreviver. Uma alteração ocasionada por uma radiação artificial, quero assim dizer aquela criada e desenvolvida pelo ser humano, pode produzir mudanças biológicas consideráveis em nossa saúde. Já há evidências, na Medicina, de que a exposição a campos eletromagnéticos de baixa freqüência pode 


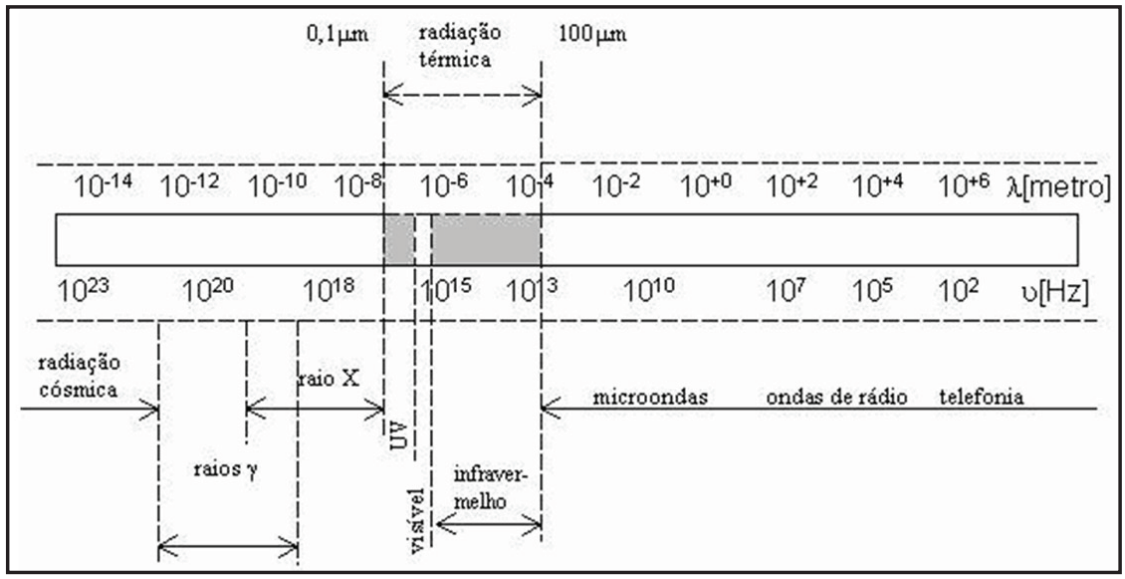

Figura 02 - Espectro de ondas eletromagnéticas

Fonte: Laboratório de Sistemas Térmicos- PUC/PR.

Simulação da Transferência de Calor por Radiação (2007).

reduzir significantemente os níveis de melatonina no corpo. Segundo Bovet (2005) Estudos da TNO - Toegepast-Natuurwestenchappelijk Onderzoek (Organização pela Pesquisa Científica Aplicada) na Holanda, concluiu que, bastam apenas 45 minutos de exposição a uma radiação eletromagnética de $0,7 \mathrm{~V} / \mathrm{m}$ (volt por metro) emitida por um aparelho celular, para se observar efeitos, inclusive graves, sobre a saúde.

$\mathrm{O}$ Eletromagnetismo trata da inter-relação entre campos elétricos e magnéticos variáveis no espaço e no tempo, bem como de sua propagação. As equações de Maxwell exprimem de forma concisa os fundamentos da teoria eletromagnética. As suas aplicações na geração, transporte e utilização de Energia e de Telecomunicações são imensas.

Os campos eletromagnéticos presentes em nosso dia-a-dia são relativamente baixos, porém se tivermos contato freqüente com equipamentos como televisores, computadores, lavadoras, microondas, dentre outros, nossa exposição torna-se bem maior. Os íons naturais do nosso organismo podem ser afetados por essas descargas elétricas provocadas por aparelhos domésticos. 
Assistimos à proliferação de usinas de força, postes de eletricidade e antenas que vão invadindo a paisagem, formando estações geradoras de energia que atendem a uma demanda fenomenal por eletricidade no mundo.

Alguns estudiosos acreditam que qualquer alteração na paisagem (como a intervenção nos rios, na terra, e também as construções) modificam o campo energético da Terra.

Os radares e antenas parabólicas, as torres de transmissão de TV, rádio, telefones celulares se somam a uma verdadeira poluição eletromagnética. Em nossa casa, na escola e no trabalho há uma abundância de cabos, fios, aparelhos e acessórios que geram campos eletromagnéticos, e quer estejamos acordados ou dormindo, não temos, na área urbana, um lugar de refúgio.

No mundo inteiro, reputados cientistas, médicos, pesquisadores e epidemiologistas vêm estudando os possíveis efeitos dos campos eletromagnéticos extremamente baixos e extremamente altos, estas pesquisas e experiências têm se tornado mais detalhadas, e as evidências sobre os possíveis efeitos nocivos só aumentam, produzindo um "liga-desliga" em nossos processos biológicos normais.

Os efeitos biológicos ocasionados pela radiação já vêm sendo estudados pela ciência há alguns anos. Está comprovado que a radiação ionizante (aquela capaz de alterar o estado físico de um átomo) pode trazer conseqüências à saúde. Mas, sejam quais forem estas conseqüências, devemos minimizar o uso da energia, tomando medidas que evitem exposições desnecessárias a campos eletromagnéticos durante longos períodos.

\section{RADIAÇÃO ELETROMAGNÉTICA IONIZANTE E NÃO- IONIZANTE}

Em 1864, o cientista James C. Maxwell comprovou, por meio de equações matemáticas, que um dado fluxo de cargas elétricas se movimentaria pelo espaço na forma de ondas de energias elétrica e magnética, com velocidade igual à da luz. Então, concluiu-se que radiação é a propagação dessa energia eletromagnética através do meio físico ou do espaço, a partir de uma fonte emissora, denominada de "irradiador".

Radiação. [Do lat. radiatione.] S.f. 1. Ato ou efeito de radiar. 2. Fís. Qualquer dos processos físicos de emissão e 
propagação de energia, seja por intermédio de fenômenos ondulatórios, seja por meio de partículas dotadas de energia cinética. 3. Fís. Energia que se propaga de um ponto a outro no espaço ou num meio material. ${ }^{6}$

Para se classificar a radiação deve-se mensurar a quantidade de energia transportada. Se falarmos de altos níveis de energia, diremos que se trata de RADIAÇÕES IONIZANTES. Se de baixos níveis de energia, serão consideradas NÃO-IONIZANTES.

A RADIAÇÃO IONIZANTE transporta energia suficiente para alterar o estado físico de átomo, ocasionando-lhe a perda de elétrons e fazendo com que se torne carregado eletricamente (ionizado). Devido à elevada energia empregada, pode haver a ionização de moléculas e átomos rompendo suas ligações internas. Ex.: Raio X e Raios Gama.

A RADIAÇÃO NÃO-IONIZANTE não transporta energia suficiente para alterar o estado físico de um átomo; desta maneira não separa os elétrons da órbita externa dos átomos. Ex.: As ondas de luz, de microondas, de rádio e antenas de telefonia.

$\mathrm{O}$ advento da telefonia wireless (sem fio) propicia-nos comodidades que trazem na bagagem um clandestino: o risco. Várias pesquisas já apontaram possíveis efeitos negativos causados pelas radiações nãoionizantes.

Na natureza a radiação é um fenômeno comum. O Sol é a principal fonte de energia eletromagnética do nosso planeta, mas há formas de radiação que não provém apenas de fontes naturais. Atividades desenvolvidas pela humanidade nos últimos cento e vinte anos provocaram, também, a irradiação de ondas eletromagnéticas. Assim, equipamentos criados pelo homem, tais como fornos de microondas, aparelhos de Raio $\mathrm{X}$, televisões, computadores, serviços de telecomunicações, de energia e de radiodifusão (com antenas espalhadas pelo ambiente urbano) só deveriam ser colocados à disposição da população se observadas as medidas legais e de segurança existentes.

Veremos a seguir os dois principais efeitos da exposição à radiação Ionizante e Não-Ionizante: o Térmico e o Atérmico. 


\section{EFEITOS TÉRMICOS}

$\mathrm{O}$ efeito térmico decorre do aquecimento do tecido. A radiação é absorvida ao nível da pele, mas também absorvida em níveis mais profundos do corpo, causando um aumento de temperatura não percebido pelos sensores térmicos naturais, já que são localizados superficialmente. Muitas vezes, esse calor gerado internamente, dependendo do tempo de exposição da intensidade do campo e da espessura do tecido, pode não ser compensado e ocasiona graves danos.

Há estudos conclusivos que apontam a possibilidade do surgimento de patologias associadas ao aumento da temperatura corporal gerada pela fricção entre as moléculas. A Organização Mundial de Saúde noticiou o aparecimento de cataratas, glaucomas, problemas cardiovasculares, ou seja, problemas nas áreas mais irrigadas do corpo humano. Porém, estes efeitos dificilmente decorrem da proximidade com estações de rádio-base, pois estes casos são constatados quando os focos de radiação estão muito próximos das pessoas, o que não ocorre com as antenas que são sempre colocadas sobre estruturas.

A Radiação Não-Ionizante pode provocar aumento da temperatura no corpo (alteração física), alterar os níveis de sódio e potássio (alteração química) e produzir alteração no sistema nervoso central (alteração biológica).

É fato que se passarmos algum tempo falando ao telefone celular sentimos um significante aumento da temperatura na região da cabeça.

A Organização Mundial de Saúde (OMS) recomenda que os pais desencorajem o uso excessivo de celular entre as crianças e adolescentes, pois suas caixas cranianas, seus cérebros e seu sistema nervoso, ainda estão em desenvolvimento, particularmente no caso das crianças.

\section{EFEITOS ATÉRMICOS}

Os efeitos biológicos atérmicos são aqueles que não dizem respeito ao aumento da temperatura ocasionado pela radiação.

Há estudos que retratam casos, decorrentes de efeitos não-térmicos, de distúrbios emocionais, do sono e de atividade epilética em algumas crianças expostas à radiação das Estações Rádio-Base. Segundo Ana Maria M. Marchesan: 
"Há também relatos de severa diminuição de produção de leite, emaciação, abortos espontâneos e natimortos em experimentos feitos com gado mantido próximo de uma ERB. " 7

Para agravar o quadro, ainda há outros depoimentos que afirmam que os efeitos atérmicos da radiação não-ionizante podem ocorrer a partir de campos eletromagnéticos com densidades de potência com níveis bem inferiores aos padrões atualmente estabelecidos no Brasil.

Hoje são adotadas as normas da ICNIRP (Internacional Comission on Non-Ionizing Radiation Protection), e a Organização Mundial de Saúde criou, em 1996, o Projeto Internacional CEM (campos eletromagnéticos), com o intuito de avaliar os possíveis efeitos sobre a saúde de campos eletromagnéticos compreendidos na freqüência de 0 (zero) a 300 (trezentos) $\mathrm{GHz}$.

No âmbito nacional, o tema vem sendo alvo de preocupações de diferentes órgãos do governo, como a FUNASA (Fundação Nacional de Saúde) que criou um grupo de trabalho com o objetivo de subsidiar o posicionamento do Ministério da Saúde relativo à exposição humana a campos eletromagnéticos provenientes de linhas de contínua e alta tensão. Este grupo divulgou suas conclusões em um relatório em março de 2004, destacando a necessidade de implementação de uma lei brasileira que fixe os limites de segurança para a exposição ocupacional a equipamentos que gerem um campo eletromagnético, na qual a metodologia de cálculo e medição visem unificar as referências técnicas utilizadas pelas empresas para caracterização dos campos produzidos pelas instalações e equipamentos terminais. As conclusões desse relatório ressaltaram o princípio da precaução como forma de enfrentarmos a incerteza científica.

\section{O PRINCÍPIO DA PRECAUÇÃO}

O Direito Ambiental busca a defesa do nosso ambiente ameaçado, vindo ao seu socorro, imaginando possíveis sistemas de prevenção e reparação para a defesa contra as agressões provocadas por nossa sociedade, sendo assim, um direito da antecipação, do futuro, da precaução.

A precaução é a ação antecipada diante de um determinado risco sobre o qual não há, ainda, uma certeza científica. Podemos dizer que, 
enquanto a prevenção se dá em relação ao perigo concreto, já comprovado, a precaução é dirigida ao perigo provável, hipotético. Este Princípio da precaução se dá em virtude de assuntos que necessitam de um estudo para a aquisição de conhecimento acerca dos efeitos a longo prazo de determinada atividade que está ligada entre a ciência e o direito. Por falta da precaução, muitos morreram em função do uso do cigarro, e muitos sofreram mutações através do uso da talidomida. Na época, a propaganda só apresentava aspectos positivos. Nos Estados Unidos, muitos usuários intensivos de celulares que contraíram cânceres no cérebro já entraram com processos contra as operadoras.

O princípio da precaução está contemplado na Lei da Política Nacional do Meio Ambiente (Lei 6.938/91), principalmente em seus artigos $4^{\circ}$, I e VI, e $9^{\circ}$, III, que tratam da necessidade de uma avaliação dos impactos ambientais de atividades potencialmente poluidoras.

Art. $4^{\circ}$ A Política Nacional do Meio Ambiente visará:

I - à compatibilização do desenvolvimento econômico-social com a preservação da qualidade do meio ambiente e do equilíbrio ecológico; (...)

IV - ao desenvolvimento de pesquisas e de tecnologias nacionais orientadas para o uso racional de recursos ambientais; (...)

Art. $9^{o}$ São instrumentos da Política Nacional do Meio Ambiente:

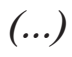

III - a avaliação de impactos ambientais; (...). ${ }^{8}$

Essa opinião preventiva também é amparada pela nossa Carta Magna, em seu art. 225, que trata do direito ao meio ambiente ecologicamente equilibrado para as presentes e futuras gerações. E, ainda, é importante lembrar que o nosso país é signatário da Declaração sobre o Meio 
os efeitos d a radiação...

Ambiente, oriunda da RIO 92, cujo princípio 15 consagra o princípio da precaução, com o objetivo de proteção ambiental e garantindo que, quando houver perigo de dano ambiental irreversível e a falta de certeza científica absoluta, não deverá ser utilizado o pretexto da não adoção de medidas eficazes em função dos custos para impedir a degradação ambiental.

A Lei dos Crimes Ambientais (Lei 9.605/98) também se refere à medida de precaução inserida no tipo penal da poluição do art. 54, § $3^{\circ}$, que diz:

Art. 54. Causar poluição de qualquer natureza em níveis tais que resultem ou possam resultar em danos à saúde humana, ou que provoquem a mortandade de animais ou a destruição significativa da flora:

Pena - reclusão, de 1 (um) a 4 (quatro) anos, e multa. ${ }^{9}$ (...)

$\S 3^{\circ}$ Incorre nas mesmas penas previstas no parágrafo anterior quem deixar de adotar, quando assim o exigir a autoridade competente, medidas de precaução em caso de risco de dano ambiental grave ou irreversível.

A legislação brasileira recomenda que em caso de dúvida se faça uso da cautela a fim de conciliar o desenvolvimento e a proteção do meio ambiente com a saúde das pessoas, para que possa haver um desenvolvimento sustentável e centrado no aspecto humano.

\section{CONCLUSÃO}

O risco provocado pelas atividades e produtos tecnológicos está sob a constante égide do medo; portanto, devemos utilizar instrumentos que possibilitem um estudo mais aprofundado sobre a radiação eletromagnética, evitando, desta maneira, desastres envolvendo a qualidade de vida de todos os seres vivos.

A sociedade contemporânea está envolvida em atividades que, apesar de extremamente sedutoras, ocultam diferentes tipos de riscos que podem ser irreversíveis. 
As entidades ambientalistas, a sociedade e seus dirigentes devem se comprometer na busca do cumprimento da legislação ambiental. A sociedade tem o direito de exigir que se estabeleçam medidas de preservação do meio ambiente, através do estudo prévio do impacto ambiental sempre que necessário.

Da mesma forma, todo cidadão tem o direito ao ambiente ecologicamente equilibrado como condição de uma melhor qualidade de vida, de ser informado sobre o quadro ambiental e sobre a atuação do poder público em sua defesa, de receber informações e obter a reparação aos danos causados ao meio ambiente, direito de viver em condições dignas. Quanto aos deveres, todo cidadão tem o dever de defender o meio ambiente junto com o Poder Público, de preservar o patrimônio ambiental, de observar a defesa ambiental na condução de qualquer atividade econômica, de recuperar o meio ambiente degradado, bem como o dever de agir, pelas vias legais, em situações de ameaça ou danos ao meio ambiente.

A sociedade, uma vez organizada, pode participar diretamente de órgãos colegiados de defesa ambiental, como ocorre com o CONAMA, bem como os Conselhos Estaduais e Municipais.

Utilizando-se da participação coletiva, podemos reivindicar, através de um requerimento assinado por pelo menos cinqüenta cidadãos, a realização de uma audiência pública para o exame dos Estudos e Relatórios de Impactos sobre o Ambiente (EIA-RIMA), com o objetivo de conhecer quais serão as consequiências da execução de uma determinada obra em relação ao meio ambiente natural, social, econômico e cultural.

E, também por meio do Ministério Público, órgãos ambientais ou associações civis, que tenha um mínimo de representatividade, com pelo menos um ano de existência e que tenham a defesa do meio ambiente incluída em seus estatutos, podem propor um Ação Civil Pública em defesa do meio ambiente.

\section{NOTAS}

1 BECK, Ulrich. Sociedade do risco - O Medo na Contemporaneidade. Incertezas fabricadas. Disponível em: <www.unisinos.br/ihu>. Acesso em: 24 jul. 2007.

2 SAUNDERS, Thomas. A síndrome do sapo cozido: Sua saúde e o ambiente que construímos. p. 54. 
3 . A síndrome do sapo cozido: Sua saúde e o ambiente que construímos. p. 18.

4 FERREIRA. Aurélio Buarque de Holanda. Novo dicionário da língua portuguesa. p. 527.

5 . Aurélio Buarque de Holanda. Novo dicionário da língua portuguesa. P. 568.

6 . Aurélio Buarque de Holanda. Novo dicionário da língua portuguesa. p. 1192

7 MARCHESAN, Ana Maria Moreira. As estações de rádio-base de telefonia celular no contexto de uma sociedade de riscos. Revista de Direito Ambiental - 39. p. 34

8 BRASIL. Constituição Federal, coletânea de legislação de direito ambiental. Org. Odete Medauar. São Paulo: Revista dos Tribunais, 2002. (RT-mini-códigos). Lei 6.938/1981 - Política Nacional do Meio Ambiente. p. 564 e566.

9 _. Constituição Federal, coletânea de legislação de direito ambiental. Org. Odete Medauar. São Paulo: Revista dos Tribunais, 2002. (RT-mini-códigos). Crimes Ambientais - Lei 9.605/1998. p. 371 .

\section{REFERÊNCIAS}

ANATEL-Agência Nacional de Telecomunicações. Campos eletromagnéticos e saúde pública: Efeitos de EMF no meio ambiente. Folha de Informação. Fevereiro de 2005. Disponível em: <http://www.anatel.gov.br/Tools/frame.asp?link=/ radiofrequencia/ oms_efeitos_de_emf_no_ambiente.pdf>. Acesso em: 27 de jun. 2007.

ABRADECEL - Associação Brasileira de Moradores e Usuários Intranqüilos com Equipamentos de Telecomunicações Celular. Legislação brasileira e normas internacionais. Disponível em: < http://www.abradecel.org.br/wd/default.asp?cat= $10 \&$ link $=154>$. Acesso em: 03 de jan. 2007.

ABRANTES, Paulo César Coelho. Imagens de natureza, imagens de ciência. Campinas: Papirus, 1998. 247 p.

BRASIL. Constituição Federal, coletânea de legislação de direito ambiental. Org. Odete Medauar. São Paulo: Revista dos Tribunais, 2002.

BRAGA, Benedito; HESPANHOL, Ivanildo; CONEJO, João G. L. et al. Introdução à engenharia ambiental. $2^{\mathrm{a}}$ ed. São Paulo: Prentice Hall, 2002. 287 p.

BECK, Ulrich. Incertezas fabricadas. Sociedade do risco: $O$ medo na contemporaneidade. p. 5 -11. IHU ONLINE. São Leopoldo, 2006. Disponível em: <www.unisinos.br/ihu>. Acesso em: 22 de jun. 2007.

DÉOUX, Suzanne; DÉOUX, Pierre. Ecologia é a saúde. O impacto da deterioração do ambiente na saúde. Lisboa : Instituto Piaget, p. 329 - 378,1996.

FERREIRA, Aurélio Buarque de Holanda. Novo dicionário da língua portuguesa. $1^{\text {a }}$ 
ed. Rio de Janeiro: Editora Nova Fronteira, p. 527 -568 -1192. 1975.

FIORILLO, Celso Antônio Pacheco. Curso de direito ambiental brasileiro. 8.ed. ver., atual. E ampl. São Paulo: Saraiva, 2007. 554 p.

ICNIRP - International Commission on Non-Ionizing Radiation Protection. Guidelines for limiting exposure to time-varying electric, magnetic and electromagnetic fields (up to $300 \mathrm{GHz}$ ). Alemanha. Disponível em: < http:/www.icnirp.org/documents/ emfgdl.pdf>. Acesso em: 27 de jun. 2007.

JUNIOR, José de Felippe. Bioeletromagnetismo: medicina com base na biofísica. Associação Brasileira de Medicina Complementar. 2004. Disponível em: <http://www. medicinacomplementar.com.br/estrategia_bioeletromagnetismo.as $>$. Acesso em: 27 ago. 2005.

LANFREDI, Geraldo Ferreira. Política ambiental: busca de efetividade de seus instrumentos. São Paulo: Revista dos Tribunais, 2002. 300p.

LORRAIN, Paul; Dale Corson e François Lorrain. Campos e ondas eletromagnéticas. 3 ed. Fundação Calouste Gulbenkian, USA, p. 539 - 562, 1988.

MARCHESAN, Ana Maria Moreira. Implicações jurídicas das radiações eletromagnéticas emanadas das estações de rádio-base de telefonia celular. Revista de Direito Ambiental. N. 24. Coord. Antônio Herman V. Benjamin e Édis Milaré. Ano 6. Publicação Oficial do Instituto "O Direito por um Planeta Verde”. Ed. Revista dos Tribunais. p. 247-256,2001.

MOUSSALE, Sérgio. Perda CPRAD. Estudo de radiações. Matérias. Auditiva X Celular. Disponível em: < http://www.cprad.com.br/cprad/materia_10.asp > . Acesso em: 18 mar. 2006.

MUSETTI, Rodrigo Andreotti. Telefonia celular: aspectos jurídico-ambientais. CMI Brasil. Disponível em: <www.cmi.org>. Acesso em 08 de jun. 2007.

SAUNDERS, Thomas. A síndrome do sapo cozido: sua saúde e o meio ambiente construído. $1^{\mathrm{a}}$ ed. São Paulo: Cultrix, 2004. 312p. 